\title{
Atividades lúdicas sobre educação nutricional como incentivo à alimentação saudável
}

\section{Ludic activities about nutritional education as an incentive to healthy alimentation}

\author{
${ }^{1}$ Lucimar Ramos do Vale lrvale@yahoo.com.br \\ 2 Maria de Fátima Alves Oliveira
}

\section{RESUMO}

Diante do processo de transição nutricional que ocorreu no Brasil nas últimas décadas, verificou-se uma mudança nos padrões alimentares provocando um aumento significativo da Obesidade em crianças e adolescentes. Como a escola é um local propício para a construção de conhecimentos e os professores são os principais disseminadores desses conhecimentos no âmbito escolar, faz-se necessário o desenvolvimento de materiais e estratégias que o auxiliem neste processo de ensino aprendizagem sobre alimentação saudável. Portanto o presente artigo tem como objetivo apresentar atividades diversificadas para escolares sobre alimentação saudável com base na ludicidade. A pesquisa é descritiva com abordagem qualitativa. Foram desenvolvidas atividades diversificadas, ministradas por 9 professores a 178 alunos, distribuídos do primeiro ao nono ano do Ensino fundamental em uma escola do município Rio Claro/RJ. Os resultados revelaram que o uso da cartilha foi positivo quanto ao incentivo à alimentação saudável. Concluímos que a cartilha que apresentava atividades diversificadas com base na ludicidade pode ser considerada um instrumento de apoio ao trabalho docente, sempre que se deseje fomentar o tema alimentação saudável no âmbito escolar.

Palavras-chave: Alimentação saudável; atividades diversificadas; Ensino fundamental.

\begin{abstract}
Faced with the nutritional transition process that occurred in Brazil in the last decades, there was a change in dietary patterns causing a significant increase in Obesity in children and adolescents. As the school is a good place to build knowledge and teachers are the main disseminators of this knowledge in the school context, it is necessary to develop materials and strategies that will help this process of teaching learning about healthy eating. Therefore the present article aims to present diversified activities for schoolchildren about healthy eating based on playfulness. The research is descriptive with a qualitative approach. Diverse activities were developed, taught by 9 teachers to 178 students, distributed from the first to the ninth year of elementary school in a school in the municipality Rio Claro / RJ. The results showed that the use of the booklet was positive regarding the incentive to healthy eating. We concluded that the booklet that presented diversified activities based on playfulness can be considered as an instrument to support the teaching work, whenever one wishes to foment the theme of healthy eating in the school context.
\end{abstract}

Keywords: Healthy eating; Diversified activities; Elementary School.

1 Centro Universitário de Volta Redonda - UniFOA, Volta Redonda, RJ.

2 Centro Universitário de Volta Redonda - UniFOA, Volta Redonda, RJ, LAEFIB - IOC - Fiocruz. 
Diante do processo de transição alimentar que vem acontecendo no Brasil, em decorrência das mudanças que ocorreram nos padrões alimentares, percebe-se a necessidade de desenvolver ações no sentido de melhorar a forma como as crianças e adolescentes estão se alimentando. Nesse sentido, alguns autores perceberam que a integração da nutrição ao ensino representa a mais eficaz forma de intervenção nutricional (PIETRUZINSKY et al., 2010).

O ensino sobre questões alimentares são articulados por intermédio da educação nutricional. Esta atua de maneira a ampliar o conhecimento alimentar dos indivíduos para que possam escolher alimentos mais saudáveis para sua alimentação. As crianças e os adolescentes, por estarem iniciando um processo de afirmação da sua identidade alimentar representam um grupo ávido por informações, dentre elas, as que têm relação com a Nutrição. Assim, o oferecimento de novas informações sobre alimentação e nutrição, auxilia na promoção da ampliação do conhecimento individual que poderá resultar em melhorias no comportamento alimentar, favorecendo não só a manutenção como a recuperação do estado nutricional (SILVA et al., 2013; TORAL, CONTI e SLATER, 2009).

Como crianças e adolescentes passam grande parte de seu tempo nas escolas e sendo essa, um local propício à construção de conhecimentos, poderia ser melhor aproveitada para o desenvolvimento de ações voltadas ao incentivo de uma alimentação saudável (BIZZO e LEDER, 2005). A escola, segundo Lima et al., (2014) portando-se como promotora de saúde deve permitir aos seus professores e alunos a aquisição de conhecimentos, habilidades e competências para que possam por em prática o que foi construído, permitindo aos sujeitos a opção por estilos de vida mais saudáveis. A produção do conhecimento no ambiente escolar para a formação de cidadãos mais críticos e mais conscientes é incentivada devido à preocupação com o avanço da Obesidade em crianças e adolescentes, por isso, planejar, desenvolver e implementar programas dirigidos a educação nutricional de forma multidisciplinar, no ambiente escolar torna-se relevante.

\section{IMPORTÂNCIA DE ATIVIDADES LÚDICAS NO DESENVOLVIMENTO DE AÇÕES EDUCATIVAS SOBRE ALIMENTAÇÃO}

Segundo Gomes e Filho (2015), atualmente ocorre uma necessidade de diferenciar o modo de ensinar, pois o aprendizado do aluno não deve permanecer limitado aos discursos dos educadores. Diante desta afirmação, perceberam que a ludicidade possui grande importância não somente para aquisição de conhecimentos dos alunos, mas também para que os professores adquiram experiências e desenvolvam seus próprios conceitos sobre os conteúdos propostos. Walter e Carvalho (2013) acrescentam que a inserção da ludicidade na prática docente é indispensável ao desenvolvimento dos aspectos motores e psicossociais dos educandos e por isso, destacam-se no cenário educacional como importante ferramenta pedagógica para o desenvolvimento físico e humano dos escolares.

Para facilitar a aprendizagem sobre a temática Silva et al., (2013) indicaram como relevantes os materiais pedagógicos sobre alimentação que servem como agentes estimulantes na construção do conhecimento. Apoiados neste pensamento desenvolveram uma pesquisa para avaliar o impacto de atividades lúdico-didáticas desenvolvidas por nutricionistas e ministradas por professores, no aprendizado dos alunos. Puderam então concluir que esse tipo de abordagem teve um efeito positivo quanto ao conhecimento destes, quando comparado ao grupo que somente recebeu informações nutricionais. Diante disso, trabalhar com ferramentas lúdicas e diversificadas no desenvolvimento de ações educativas em nutrição torna-se essencial para facilitar o processo de ensino aprendizagem no ambiente escolar.

Reforçando essa concepção sobre o lúdico no contexto escolar, Gonçalves e Ribeiro (2014) relataram em seu estudo sobre a importância da ludicidade frente a percepção e a prática de professores, que eles compreendiam que a brincadeira, a alegria e a diversão contribuíam expressivamente na aprendizagem. 
Segundo Pinto e Tavares (2010), atividades lúdicas exercem uma função importante na aprendizagem por reunir dentro de uma mesma situação, a brincadeira e o educar. Utilizadas em sala de aula, cria um espaço de reelaboração do conhecimento vivenciado e constituído com o grupo ou individualmente. Segundo os autores do artigo, o lúdico não pode ser visto apenas como um passatempo, mas sim como uma ferramenta de grande valia na aprendizagem em geral, inclusive de conteúdos, pois propõe problemas, cria situações e assume condições na interação, criando a possibilidade de aproximar o educando de conhecimentos que podem levá-lo a criar soluções para situações problemas.

\section{OBJETIVO}

Diante da importância do desenvolvimento de ações e estratégias sobre alimentação saudável nas escolas, o presente artigo tem como objetivo apresentar atividades diversificadas para escolares sobre alimentação saudável com base na ludicidade.

\section{METODOLOGIA}

O presente artigo traz um recorte da dissertação intitulada Ferramenta Pedagógica para o Ensino de Nutrição que foi apresentada no exame de qualificação da autora do estudo no Programa de Mestrado Profissional em Ensino de Ciências da Saúde e de Meio Ambiente.

O estudo teve início após aprovação do Comitê de Ética e Pesquisa em Seres Humanos - CoEPS, do Centro Universitário de Volta Redonda - UniFOA, sob parecer nº 40609414.8.0000.5237 em 09 de setembro de 2015.

Por tratar-se de um curso de Mestrado Profissional em Ensino em Ciências da Saúde e do Meio Ambiente, fez-se necessário o desenvolvimento de um produto voltado ao ensino, sendo que neste trabalho o tema era voltado ao ensino em saúde. Como a ludicidade influencia de forma positiva o processo ensino e aprendizagem (NETO, 2014), foi elaborada uma cartilha para uso de professores, contendo atividades lúdicas e diversificadas sobre alimentação saudável. Para tanto foi realizada uma pesquisa descritiva de abordagem qualitativa.

As atividades pensadas para compor essa cartilha foram elaboradas a partir de dois parâmetros. Inicialmente, por meio de uma revisão da literatura que está contida no texto da dissertação que revelou na maioria dos estudos analisados, nas diferentes regiões do Brasil, hábitos e consumo inadequado de alimentos entre os jovens. De modo geral o público investigado apresentava baixo consumo de frutas, legumes e verduras, preferência por alimentos não saudáveis com excesso de açúcar e gorduras, omissão de refeições importantes, consumo de alimentos com excesso de sódio, hábito de comer assistindo televisão o que possivelmente leva ao consumo exagerado de alimentos, número significativo de escolares com Obesidade, entre outros problemas. Portanto, essas questões foram norteadoras para a construção das atividades.

Posteriormente, utilizamos o trabalho de Maranhão (2007) para compreender como crianças e adolescentes apresentavam-se em relação ao seu desenvolvimento cognitivo para brincadeiras e jogos, e assim analisar qual atividade seria a mais adequada para cada faixa etária. Com base nestas informações foi construído um quadro sobre essas características (Quadro 1). 


\section{Quadro 1 - Características de crianças e adolescentes em cada faixa etária}

\begin{tabular}{|c|c|c|c|}
\hline $\begin{array}{l}\text { Faixa } \\
\text { etária }\end{array}$ & $\begin{array}{l}\text { Como a criança apresenta-se nesta faixa etária diante } \\
\text { de atividades lúdicas }\end{array}$ & $\begin{array}{l}\text { Anos } \\
\text { escolares que } \\
\text { correspondem } \\
\text { a faixa etária }\end{array}$ & Atividades propostas na cartilha \\
\hline \multirow[b]{2}{*}{ 4-7 anos } & \multirow{2}{*}{$\begin{array}{l}\text { Na fase dos quatro a sete anos os músculos responsáveis } \\
\text { pela coordenação motora fina serão desenvolvidos, } \\
\text { através de brincadeiras que sejam necessários picar papel, } \\
\text { recortar, amassar, colorir etc. Os jogos também assumem } \\
\text { um papel importante no desenvolvimento das crianças, } \\
\text { pois são vistos com mais seriedade perante suas regras. }\end{array}$} & $\begin{array}{l}1^{\circ} \text { ano } \\
(5-6 \text { anos })\end{array}$ & $\begin{array}{l}\text { Elaboração de máscaras de vegetais } \\
\text { para colorir e recortar. }\end{array}$ \\
\hline & & $\begin{array}{l}2^{\circ} \text { ano } \\
(6-7 \text { anos })\end{array}$ & $\begin{array}{l}\text { Elaboração de jogo da memória com } \\
\text { imagens de vegetais para colorir e } \\
\text { recortar. }\end{array}$ \\
\hline \multirow{3}{*}{$\begin{array}{l}7-10 \\
\text { anos }\end{array}$} & \multirow{3}{*}{$\begin{array}{l}\text { Nesta fase o corpo vai ocupar um lugar de destaque } \\
\text { em suas brincadeiras. Por meio da curiosidade será } \\
\text { capaz de romper os esquemas já existentes, estará mais } \\
\text { questionadora, gostará de desafios, de resolver situações } \\
\text { problemas. A criatividade será sua principal característica } \\
\text { nesta fase de desenvolvimento. }\end{array}$} & $\begin{array}{l}3^{\circ} \text { ano } \\
(7-8 \text { anos })\end{array}$ & $\begin{array}{l}\text { Elaboração de jogo do mico com } \\
\text { imagens de vegetais para colorir e } \\
\text { recortar. }\end{array}$ \\
\hline & & $\begin{array}{l}4^{\circ} \text { ano } \\
(8-9 \text { anos })\end{array}$ & $\begin{array}{l}\text { Elaboração de caderno de receitas } \\
\text { saudáveis }\end{array}$ \\
\hline & & $\begin{array}{l}5^{\circ} \text { ano } \\
(9-10 \text { anos })\end{array}$ & $\begin{array}{l}\text { Elaboração de cartazes com o tema: } \\
\text { "Meu corpo é o que eu como". }\end{array}$ \\
\hline \multirow{4}{*}{$\begin{array}{l}\text { A partir } \\
\text { de } 11 \\
\text { anos }\end{array}$} & \multirow{4}{*}{$\begin{array}{l}\text { Na fase dos } 11 \text { anos em diante os jogos tornam-se ainda } \\
\text { mais atraentes, pois os jovens adoram a sensação da } \\
\text { conquista de algo novo e as atividades intelectuais vão } \\
\text { atrair suas atenções. O jovem nesta fase já consegue } \\
\text { analisar antes de agir, portanto discutir, pesquisar, estar } \\
\text { em contato com o grupo, arriscar-se e os desafios dos } \\
\text { jogos serão marcantes nesta fase. A expressão artística } \\
\text { também é outra atividade que os atrairá e assim sua } \\
\text { criatividade será estimulada. }\end{array}$} & $\begin{array}{l}6^{\circ} \text { ano } \\
(10-12 \text { anos })\end{array}$ & Elaboração de cardápio saudável \\
\hline & & $\begin{array}{l}7^{\circ} \text { ano } \\
(12-13 \text { anos })\end{array}$ & $\begin{array}{l}\text { Brincadeira denominada "Batata } \\
\text { quente saudável” }\end{array}$ \\
\hline & & $\begin{array}{l}8^{\circ} \text { ano } \\
(13-14 \text { anos })\end{array}$ & $\begin{array}{l}\text { Brincadeira denominada "Mitos e } \\
\text { Verdades sobre alimentação" }\end{array}$ \\
\hline & & $\begin{array}{l}9^{\circ} \text { ano } \\
(14-15 \text { anos })\end{array}$ & $\begin{array}{l}\text { Atividade denominada “Compositor } \\
\text { saudável”, consiste na reinvenção de } \\
\text { uma música. }\end{array}$ \\
\hline
\end{tabular}

Fonte: Maranhão (2007) adaptado pelas autoras.

Após o processo de construção e finalização da cartilha iniciamos o processo de aplicação das atividades pelos professores. O trabalho foi desenvolvido em uma escola municipal do município de Rio Claro - RJ. O público alvo deste estudo foi constituído de professores do primeiro ao nono ano do Ensino Fundamental que seriam os responsáveis pela aplicação e desenvolvimento das atividades contidas na cartilha. Os professores foram convidados a desenvolver as atividades nos respectivos anos escolares como forma de avaliarmos as atividades da cartilha. Participaram das atividades 9 professores e 178 alunos.

A avaliação da cartilha foi feita através de observação no desenvolvimento das atividades nas salas de aula com os alunos e por meio de conversa informal com os professores, com objetivo de ouvir a opinião deles sobre o material elaborado. Após as observações no desenrolar das atividades, todas as sugestões dadas pelos professores serviu-nos de base para possíveis modificações nas atividades da cartilha.

Após o desenvolvimento de todas as atividades, nos diferentes anos de escolaridade, a versão final da cartilha recebeu o título de “Alimentação saudável também se aprende na escola: é com você professor!”.

\section{Cartilha “Alimentação saudável também se aprende na escola: é com você professor!”}

Primeiro ano: elaboração de máscaras para recortar e colorir com moldes de frutas, legumes e verduras, e uma música para cantarem juntos sobre o tema trabalhado. Em seguida sugerimos a preparação de uma salada de frutas. Indicamos também um material de apoio em forma de vídeos que podem ser acessados na internet.

Segundo ano: elaboração de um jogo da memória contendo imagens de frutas, legumes e verduras, e uma consulta por nomes de diferentes vegetais que podem ser consumidos diariamente, além de um material de apoio 
em forma de vídeos que podem ser acessados na internet. Em seguida sugerimos a preparação de uma salada de frutas.

Terceiro ano: elaboração de um jogo do tipo “Mico Preto”, que é popular nas brincadeiras infantis, para recortar e colorir, além de uma consulta sobre os alimentos que devemos evitar e os que podemos comer diariamente. Em seguida sugerimos a preparação de uma salada de frutas.

Quarto ano: elaboração de um caderno de receitas saudáveis, que apresentem alimentos nutritivos como frutas, legumes e verduras como ingredientes. Faz parte desta atividade uma consulta sobre alimentos saudáveis e não saudáveis, assim como investigação sobre os alimentos consumidos pelos familiares em diferentes gerações. Em seguida sugerimos a preparação de uma salada de frutas.

Quinto ano: uma consulta realizada pelos alunos sobre o tema Obesidade e a busca por figuras de alimentos saudáveis e não saudáveis que serão utilizados na construção de cartazes. Em seguida sugerimos uma dinâmica e a preparação de uma salada de frutas.

Sexto ano: uma consulta realizada pelos alunos sobre os tipos de alimentos saudáveis que podem ser consumidos nas principais refeições. Em seguida na elaboração com massa de modelar ou recortes de revistas/ encartes de alimentos saudáveis que podem compor as seis refeições diárias: desjejum, colação, almoço, lanche da tarde, jantar e ceia. Também fará parte desta atividade a elaboração de uma redação e a confecção de uma salada de frutas.

Sétimo ano: uma brincadeira conhecida pelas crianças como "Batata Quente”, na qual os alunos responderão a perguntas embasadas em uma consulta realizada por eles sobre Obesidade. Em seguida sugerimos a preparação de uma salada de frutas.

Oitavo ano: elaboração de uma atividade apresentando mitos e verdades sobre a alimentação. Fará parte desta atividade uma consulta sobre o tema e uma brincadeira em que o professor fará perguntas e os alunos poderão se posicionar a respeito. As respostas corretas serão reveladas pelo professor possibilitando uma reflexão quando houver erros. Em seguida sugerimos a preparação de uma salada de frutas.

Nono ano: elaboração de uma letra de música utilizando como base a música popular brasileira "Não é proibido”, de Marisa Monte, que fala sobre o consumo de alimentos não saudáveis. Fará parte desta atividade uma consulta sobre alimentos saudáveis e não saudáveis, um material de apoio em forma de documentário acessado na internet e a preparação de uma salada de frutas.

\section{RESULTADOS E DISCUSSÃO}

Após a elaboração da cartilha que foi posteriormente avaliada junto aos professores do ensino fundamental nos diferentes anos de escolaridade com os respectivos alunos, durante o desenvolvimento das atividades que compõem a cartilha, através das ações e falas dos professores, nos foi possível observar, analisar e interpretar algumas questões que discutiremos a seguir.

Da totalidade de nove professores que desenvolveram as atividades e manifestaram suas considerações particulares sobre a temática trabalhada, todos ressaltaram sobre a importância no desenvolvimento de ações que incentivam a alimentação saudável nas escolas. Acreditamos que essa importância foi percebida pelos professores diante da afirmação de que os alunos não estavam se alimentando de forma correta, por observarem no cotidiano deles o consumo de alimentos não saudáveis como refrigerantes, biscoitos recheados, salgadinhos e doces, que eram levados como opção de merenda no intervalo escolar. Além disso, muitos destes alunos não consumiam a merenda escolar que era saudável, segundo a visão de alguns professores. 
De maneira geral, percebemos que o estímulo para o consumo de alimentos nem sempre saudável é bem maior do que o quantitativo de ações de incentivo a uma alimentação saudável na escola. Em relação ao estímulo, Ruwer e Mainbourg (2015), mencionam que a publicidade está relacionada a essa questão, pois possui uma carga muito forte de incentivo aos alimentos, sendo que a maioria é industrializada e não recomendada para consumo frequente. Devido a facilidade de acesso e praticidade, acabam sendo escolhidos para serem levados como merenda para a escola.Como o mercado de trabalho se expandiu e a mão de obra feminina foi inserida neste meio, a figura materna, que anteriormente provia a alimentação mais natural em casa, devido ao ritmo de vida acelerado, acaba por procurar alimentos mais práticos. Com isso, toda a família, mas principalmente as crianças e os adolescentes que são dependentes financeiramente dos pais, acabam sofrendo essa influência - consumo de refeições mais rápidas e industrializadas (RUWER e MAINBOURG, 2015).

Ainda em relação ao estímulo a uma alimentação pouco saudável, existe também a influência de propagandas de alimentos nas escolhas alimentares de crianças e adolescentes que os incentiva ao consumo de alimentos inadequados e que segundo Mattos et al., (2010) são os preferidos por grande parte de crianças e adolescentes. Portanto, incentivar o consumo de alimentos adequados para este público torna-se essencial, inclusive nas escolas.

Outro fator importante a ser discutido relaciona-se ao processo de transição nutricional que ocorreu no Brasil nas últimas décadas, pois vemos esta situação também como um fator relevante, que modificou o padrão alimentar da população. Jaime e Santos (2014) recapitularam que a sociedade brasileira nas últimas décadas, sofreu grandes transformações sociais que resultaram em mudanças no seu padrão de consumo alimentar, de saúde e de nutrição. Essas transformações agregaram conquistas significativas em relação ao declínio da desnutrição, porém acompanhada por outros problemas nutricionais, sendo um deles, o Sobrepeso e a Obesidade.O padrão de consumo da população passa a ser predominantemente industrializado, com diminuição dos alimentos pouco processados e mais naturais. Desta forma, o processo de transição nutricional traz consigo a preocupação e o desafio de se desenvolver meios de melhorar questões relacionadas a alimentação e nutrição da população (JAIME e SANTOS, 2014).

Assim sendo, percebemos que a escola emerge como um espaço importante para o desenvolvimento de ações e estratégias, e que por meio destas, os alunos podem construir conhecimentos sobre educação alimentar e nutricional de maneira que essas informações acabam chegando ao lar, através dos alunos. Essa concepção foi percebida e relatada pela maioria dos professores da pesquisa. Segundo os professores, as atividades da cartilha seriam uma forma de incentivar o consumo de alimentos saudáveis, pois além de perceberem essa necessidade em relação aos alunos, percebiam também a necessidade de que os pais deveriam se preocupar mais com a alimentação dos filhos.

Portanto, abordamos na cartilha o incentivo à alimentação saudável, mas também desenvolvemos atividades que atentam para o tema Obesidade, devido ao cenário atual observado e mediante trabalhos e estudos realizados por diferentes pesquisadores sobre o estado nutricional de escolares que evidenciam esta realidade. Justificando esta afirmação, primeiramente em relação às crianças citamos o trabalho de Almeida et al., (2016) que através de uma revisão de literatura tinha como um dos objetivos pesquisar a prevalência de Obesidade de crianças em fase escolar. Encontraram altos índices destas doenças nos artigos escolhidos para compor a revisão. Dos artigos selecionados que juntos somavam um total de 625 crianças, os pesquisadores detectaram que 30\% destas crianças da amostra estavam Obesas ou com Sobrepeso.

Em seguida, em relação ao público infanto-juvenil descrevemos o trabalho de Cesar e Silva (2015) que analisaram os dados disponíveis na Pesquisa de Orçamentos Familiares - POF (2008-2009), disponibilizado em 2011. Após análise, os pesquisadores perceberam que a proporção de Obesidade cresce em adolescentes com idades entre 10 a 19 anos, tendo aumentado em um ritmo acelerado nesta população. Como a Obesidade está relacionada ao aparecimento de outras doenças que da mesma forma são relevantes, e por ser uma patologia de ordem multifatorial, pode ser considerada como um problema de saúde pública. 
Como um dos fatores que está diretamente relacionado com a Obesidade é a inadequação do consumo alimentar (ALBUQUERQUE et al., 2016), e como os hábitos alimentares de crianças e adolescentes escolares apresentam-se de forma pouco saudável, elaboramos a cartilha com ênfase no incentivo a uma alimentação saudável. Segundo a fala dos professores da pesquisa, ações de incentivo a uma alimentação saudável podem fazer com que os alunos prestem mais atenção a qualidade da sua alimentação e assim modifiquem hábitos, quando necessário. Portanto, além de elaborarmos as atividades de incentivo, tivemos a preocupação em incentivar também a degustação de alguns alimentos que são considerados saudáveis. Para tanto, utilizamos como sugestão na cartilha a produção e consumo de uma salada de frutas.

Cruz, Santos e Cardoso (2015) atentaram em seu estudo para essa questão da necessidade de incentivar o consumo de frutas nas escolas, pois observaram um baixo consumo deste alimento. Portanto, desenvolveram e implementaram um programa educativo voltado à orientação e promoção de práticas alimentares saudáveis para crianças em fase escolar, intitulado "Sexta é dia de fruta? É sim senhor". Antes de desenvolver e implementar as ações educativas, $47 \%$ das crianças investigadas não levavam frutas para o lanche na escola. Após o desenvolvimento das atividades que nortearam o programa, os pesquisadores perceberam uma melhora significativa no consumo de frutas destas crianças que passaram a levá-las e consumi-las na escola com maior frequência. Reforçando a importância de desenvolver ações de incentivo a uma alimentação saudável nas escolas.

Ações educativas em alimentação e nutrição proporcionam a construção do conhecimento em relação a temática, incentivam e melhoram a frequência de práticas alimentares saudáveis. Para tanto, essas intervenções devem ir muito além de promover somente conhecimentos nutricionais (LAZARI et al., 2012). Destaca-se a urgência na construção de novas perspectivas para as práticas de educação alimentar e nutricional em que estas não fiquem situadas em modelos tradicionais baseados somente na transmissão de informações com predominância de palestras e/ou a produção de materiais informativos, inclusive no âmbito das políticas públicas em alimentação e nutrição (SANTOS, 2012).

O desenvolvimento das atividades da cartilha, de acordo com a fala dos professores, despertou o interesse dos alunos quanto às questões trabalhadas, possivelmente pela presença das atividades diversificadas, apoiadas na ludicidade e que se diferenciavam do que tradicionalmente estão acostumados no dia a dia da sala de aula. Segundo Gomes e Filho (2015), atualmente ocorre uma necessidade de diferenciar o modo de ensinar, pois o aprendizado do aluno não deve permanecer limitado aos discursos dos educadores. Diante desta afirmação, perceberam que a ludicidade possui grande importância não somente para aquisição de conhecimentos dos alunos, mas também para que os professores adquiram experiências e desenvolvam seus próprios conceitos sobre os conteúdos propostos. Walter e Carvalho (2013) acrescentam que a inserção da ludicidade na prática docente é indispensável ao desenvolvimento dos aspectos motores e psicossociais dos educandos e por isso, destacam-se no cenário educacional como importante ferramenta pedagógica para o desenvolvimento físico e humano dos escolares.

Reforçando essa concepção sobre o lúdico no contexto escolar, Gonçalves e Ribeiro (2014) relataram em seu estudo sobre a importância da ludicidade frente a percepção e a prática de professores. Eles compreendiam que a brincadeira, a alegria e a diversão contribuem expressivamente na aprendizagem. As crianças que participaram do mesmo estudo relataram uma preferência por aulas dinâmicas e diversificadas com a presença de atividades práticas, jogos e brincadeiras. Para os autores a ludicidade além de possibilitar o desenvolvimento físico, afetivo, motor e intelectual, pode criar ocasiões propícias à construção do conhecimento.

Os professores participantes do nosso estudo não relataram dificuldades ao desenvolver as atividades da cartilha, porém alguns relataram não trabalhar esta temática com frequência, apesar de reconhecerem sua importância no ambiente escolar. Um dos motivos citados foi a falta de tempo, pois segundo a fala de uma professora, o ano letivo passa muito rápido e acaba não dando tempo de trabalhar os temas transversais. Sendo assim, a partir da utilização da cartilha, que apresentava atividades que estimulam uma alimentação saudável, por meio de atividades lúdicas e interativas foi possível sensibilizar alunos e professores em relação a promoção da saúde e prevenção de doenças, além de oportunizar aos professores a possibilidade de trabalhar o tema na escola. 


\section{CONSIDERAÇÕES FINAIS}

Diante da importância do desenvolvimento de ações e estratégias sobre alimentação saudável nas escolas, o presente artigo apresentou uma cartilha com atividades diversificadas para escolares sobre alimentação saudável com base na ludicidade, que foi utilizada na escola com alunos do $1^{\circ}$ ao $9^{\circ}$ ano de escolaridade do Ensino Fundamental. A interação entre alunos e professores durante o desenvolvimento das diferentes atividades mostrou que a mesma foi bem aceita entre os envolvidos. Partindo do pressuposto de que a alimentação é essencial para a vida e que esta deve ser mais saudável possível, como forma de manter a saúde e prevenir doenças, o uso da cartilha pode ser considerado um instrumento de apoio ao trabalho docente, sempre que se deseje fomentar o tema alimentação saudável no âmbito escolar.

\section{REFERÊNCIAS}

ALBUQUERQUE, Parente et al. Relação da obesidade com o comportamento alimentar e o estilo de vida de escolares brasileiros. Nutrição Clínica Dietética Hospitalar, v. 36, n. 1, p. 17-23, jul./out. 2015.

ALMEIDA, Maicon Alves de et al. Revisão sistemática: um estudo sobre a prevalência da obesidade em crianças de idade escolar. In: ENCONTRO REGIONAL DOS ESTUDANTES DE EDUCAÇÃO FÍSICA, n. XXII, 2016. João Pessoa. Anais EREEF. João Pessoa, 2016.

BIZZO, Maria Letícia Galluzzi; LEDER, Lídia. Educação nutricional nos parâmetros curriculares nacionais para o ensino fundamental. Revista de Nutrição, Campinas, v. 18, n. 5, p. 1-6, set./out. 2005.

CESAR, Denise Jovê; SILVA, Rafaelly Bruna Martins da. Obesidade em escolares: um olhar a partir dos dados da Pesquisa de Orçamentos Familiares. Ensaio Acadêmico, v. 2, n. 2, p. 178-183, 2015.

CRUZ, Camila de Oliveira; SANTOS, Jéssica Mendonça dos; CARDOZO, Tatiana Silveira Feijó. Aplicação do Programa de Educação Nutricional: Sexta é dia de fruta? É sim senhor! Revista Rede de Cuidados em Saúde, v. 9, n. 3, p. 1-12, 2015.

GOMES, LázaraWelyane Martins; FILHO, Aroldo Vieira de Moraes. Alimentos Transgênicos: utilização de metodologia alternativa para otimização do processo de ensino aprendizagem. Revista Eletrônica da Faculdade de Araguaia, v. 7, p. 325-336, 2015.

GOMES, LázaraWelyane Martins; FILHO, Aroldo Vieira de Moraes. Alimentos Transgênicos: utilização de metodologia alternativa para otimização do processo de ensino aprendizagem. Revista Eletrônica da Faculdade de Araguaia, v. 7, p. 325-336, 2015.

GONÇALVES, Josiane Peres; RIBEIRO, Lizíria Gabriela Soares. Ludicidade no $1^{\text {o }}$ ano do Ensino Fundamental: percepção e prática das professoras. Educação. Unisinos, v. 18, n. 3, p. 258-270, set./dez. 2014.

GONÇALVES, Josiane Peres; RIBEIRO, Lizíria Gabriela Soares. Ludicidade no $1^{\circ}$ ano do Ensino Fundamental: percepção e prática das professoras. Educação. Unisinos, v. 18, n. 3, p. 258-270, set./dez. 2014.

JAIME, Patricia Constante; SANTOS, Leonor Maria Pacheco. Transição nutricional e a organização do cuidado em alimentação e nutrição na Atenção Básica em saúde. Divulgação em Saúde para Debate, Rio de Janeiro, n. 51, p. 72-85, out. 2014.

LAZARI, Taciane Ávila et al. Importância da educação nutricional na infância. In: CONGRESSO MULTIPROFISSIONAL EM SAÚDE, n. VI, 2012. Londrina. VI Congresso Multiprofissional em Saúde. Londrina: UniFil, 2012. P. 100. 
LIMA, Ana aula Santos de et al. O ensino multidisciplinar como estratégia pedagógica para melhoria do conhecimento nutricional de estudantes do ensino fundamental. Revista Ciências \& Ideias, Santa Maria, v. 5, n. 1, p. 67-82, jan./abr. 2014.

MARANHÃO, Diva Nereida Marques Machado. Ensinar Brincando: a aprendizagem pode ser uma grande brincadeira. 4 ed. Rio de Janeiro: Wak, 2007. 126 p.

MATTOS, Marilia Costa et al. Influência de propagandas de alimentos nas escolhas alimentares de crianças e adolescentes. Psicologia: teoria e prática, São Paulo, v. 12, n. 3, p. 01-14, mar. 2010.

NETO, Vinícius Lino de Souza et al. Ações lúdicas como ferramenta para prevenção da obesidade do pré-escolar: relato de experiência. Revista de Enfermagem UFSM, Santa Maria, v. 4, n. 4, p. 850-857, out./dez. 2014.

PIETRUSZYNSKI, Ellen Beatriz et al. Práticas pedagógicas envolvendo a alimentação no ambiente escolar: apresentação de uma proposta. Revista Teoria e Prática da Educação, v. 13, n. 2, p. 223-229, maio/ago. 2010.

PINTO, Cibele Lemes; TAVARES, Helenice Maria. O lúdico na aprendizagem: apreender e aprender. Revista da Católica, Uberlândia, v. 2, n. 3, p. 226-235, 2010.

RUWER, Cristiane Marisa; MAINBOURG, Evelyne Marie Therese. Promoção da alimentação saudável em escolas particulares. Revista Visa em Debate, v. 3, n. 1, p. 67-74, 2015.

SANTOS, Ligia Amparo da Silva. O fazer educação alimentar e nutricional: algumas contribuições para reflexão. Ciência \& Saúde Coletiva, v. 17, n. 2, p. 453-462, nov. 2012.

SILVA, Margareth Xavier et al. Abordagem lúdico-didática melhora os parâmetros de educação nutricional em alunos do ensino fundamental. Ciências \& Cognição, Rio de Janeiro, v. 18, n. 2, p. 136-148, ago./out. 2013.

SILVA, Margareth Xavier et al. Projeto piloto: considerações de alunos do ensino fundamental sobre método de educação alimentar. Em Extensão, Uberlândia, v. 12, n. 2, p. 51-64, jul./dez. 2013.

TORAL, Natacha; CONTI, Maria Aparecida, SLATER, Betzabeth. A alimentação saudável na ótica dos adolescentes: percepções e barreiras à sua implementação e características esperadas em materiais educativos. Caderno de Saúde Pública, Rio de Janeiro, v. 25, n.11, p. 2386-2394, nov. 2009.

WALTER, Manoel Soriano; CARVALHO, Francimeiry. Atuação lúdico-metodológica dos professores da educação infantil das escolas da rede pública da zona urbana do município de Floriano - Piauí: perspectiva didática. Form@re, Teresina, v. 1, n. 1, p. 130-139, jul./dez. 2013.

WALTER, Manoel Soriano; CARVALHO, Francimeiry. Atuação lúdico-metodológica dos professores da educação infantil das escolas da rede pública da zona urbana do município de Floriano - Piauí: perspectiva didática. Form@re, Teresina, v. 1, n. 1, p. 130-139, jul./dez. 2013. 